\title{
Systematic Review and Meta-Analysis of the Association between Ambient Nitrogen Dioxide and Respiratory Disease in China
}

\author{
Jiyao Sun ${ }^{1}$, Andrew J. Barnes ${ }^{2}$, Dongyang He ${ }^{1}$, Meng Wang ${ }^{1}$ and Jian Wang ${ }^{1, *}$ \\ 1 School of Health Care Management, Shandong University, Key Laboratory of Health Economics and Policy \\ Research, National Health and Family Planning Commission of People's Republic of China (NHFPC), \\ Shandong University, 44 West Wenhua Road, Jinan 250012, China; sunjiyao108@163.com (J.S.); \\ hedy_1993@126.com (D.H.); wangmenghlj@163.com (M.W.) \\ 2 Department of Health Behavior and Policy, School of Medicine, Virginia Commonwealth University, \\ 830 E Main St., Richmond, VA 23219, USA; andrew.barnes@vcuhealth.org \\ * Correspondence: jianw@sdu.edu.cn; Tel.: +86-531-8838-2210
}

Academic Editor: Paul B. Tchounwou

Received: 6 May 2017; Accepted: 14 June 2017; Published: 16 June 2017

\begin{abstract}
Objective: This study aimed to assess the quantitative effects of short-term exposure of ambient nitrogen dioxide $\left(\mathrm{NO}_{2}\right)$ on respiratory disease (RD) mortality and $\mathrm{RD}$ hospital admission in China through systematic review and meta-analysis. Methods: A total of 29 publications were finally selected from searches in PubMed, Web of Science, CNKI and Wanfang databases. Generic inverse variance method was used to pool effect estimates. Pooled estimates were used to represent the increased risk of RD mortality and RD hospital admission per $10 \mu \mathrm{g} / \mathrm{m}^{3}$ increase in $\mathrm{NO}_{2}$ concentration. Results: Positive correlations were found between short-term $\mathrm{NO}_{2}$ exposure and RD in China. RD mortality and RD hospital admission respectively increased by $1.4 \%$ (95\% CI: $1.1 \%$, $1.7 \%$ ) and $1.0 \%$ (95\% CI: $0.5 \%, 1.5 \%)$ per $10 \mu \mathrm{g} / \mathrm{m}^{3}$ increase in $\mathrm{NO}_{2}$ concentration. Differences were observed across geographic regions of China. The risk of $\mathrm{RD}$ mortality due to $\mathrm{NO}_{2}$ was higher in the southern region $(1.7 \%)$ than in the north $(0.7 \%)$. Conclusions: Evidence was found that short-term exposure to $\mathrm{NO}_{2}$ was associated with an increased risk of RD mortality and RD hospital admission in China and these risks were more pronounced in the southern regions of the country, due in part to a larger proportion of elderly persons with increased susceptibility to $\mathrm{NO}_{2}$ in the population compared with the north.
\end{abstract}

Keywords: nitrogen dioxide; respiratory disease; hospital admission; China

\section{Introduction}

China has maintained a rapid rate of growth in its economy over the past three decades. However, the economic boom came the cost of worsening air quality [1]. Ambient air pollution, which is composed of both solid particles and gaseous pollutants, has been demonstrated to be associated with various adverse effects on human health [2]. Fuel combustion, automobile exhaust, industrial production has increased nitrogen dioxide $\left(\mathrm{NO}_{2}\right)$ in the air [3]. Satellite data has indicated a significant increase of about 50\% over the industrial areas of China from 1996 to 2004 [4]. Although many epidemiological studies have shown strong evidence linking air pollutants, such as particulates, $\mathrm{NO}_{2}$, sulfur dioxide $\left(\mathrm{SO}_{2}\right)$, ozone with adverse health effects [3], it is still worth noting that $\mathrm{NO}_{2}$ which is a highly reactive, nitrogen-centred free radical, poorly water-soluble gas deposited peripherally in the lungs [5], probably more easily contribute to various respiratory diseases (RD), such as respiratory inflammation, responsiveness, infections and symptoms [6]. From a pathophysiological point of 
view, the main mechanism of $\mathrm{NO}_{2}$ toxicity has been suggested to involve lipid peroxidation in cell membranes and various actions of free radicals on structural and functional molecules [5], which could cause an airway inflammation, probably restricted to the smaller airways and the terminal bronchioles, at least after a single exposure [7].

More epidemiological evidence has also been established in recent years documenting that the $\mathrm{NO}_{2}$ concentration is increasing and is significantly correlated with increasing the risk of RD. As for mortality, Chen's [3] study in 17 Chinese cities and Tao's [8] study in the Pearl River Delta have estimated significant increases in $\mathrm{RD}$ mortality associated with short-term $\mathrm{NO}_{2}$ exposure. Wong [9] and Yang [10] also conducted studies from Hong Kong and Taipei that show consistent results. As for hospital admissions, Wong [11] and Zhang [12] investigated whether increases in $\mathrm{NO}_{2}$ concentration correspond to increases in RD hospital admissions in Hong Kong and Guangzhou. Tao [13] and $\mathrm{Liu}$ [14] also found positive associations between short-term $\mathrm{NO}_{2}$ exposure and $\mathrm{RD}$ hospital admissions in China.

With the increase of epidemiological studies, a systematic review and meta-analysis are needed to integrate the existing evidence on the correlation between $\mathrm{NO}_{2}$ and $\mathrm{RD}$ in Chinese population [15]. Some meta-analysis studies on the short-term adverse health effects of $\mathrm{NO}_{2}$ have been carried out in the United States [16,17], Canada [18] and Europe $[5,19,20]$. However, due to the difference of exposure level, air pollutant composition, and demographic characteristics between China and other countries, the exposure-response functions observed in other countries may not generalize to the Chinese context [21].

To the authors' knowledge, quantitative systematic reviews and meta-analyses focusing on the association between $\mathrm{NO}_{2}$ and $\mathrm{RD}$ in China are limited. After a systematic database search, only three meta-analysis studies [22-24] were identified. These studies examined the epidemiological evidence prior to 2015, and only one of them showed a positive correlation between $\mathrm{NO}_{2}$ and RD hospital admission. Since 2015, the pace of epidemiological studies [25-29] published on the quantitative association between $\mathrm{NO}_{2}$ and $\mathrm{RD}$ has accelerated. However, no recent meta-analysis has been conducted to systematically review them. Therefore, the aim of the present study is to systematically collect and summarize the epidemiological evidence to date on RD mortality and RD hospital admission related to $\mathrm{NO}_{2}$ observed in the Chinese population published in either the English or Chinese peer-reviewed literature, in order to provide more up-to-date evidence to inform health impact assessment and air quality improvement.

\section{Materials and Methods}

\subsection{Databases}

We searched in the PubMed, Web of Science, China National Knowledge Infrastructure (CNKI) and Wanfang databases (last entry on 31 December 2016) for epidemiological literature on RD mortality and RD hospital admission due to ambient $\mathrm{NO}_{2}$ air pollution in China using the following terms: (1) nitrogen dioxide, $\mathrm{NO}_{2}$, air pollution; (2) respiratory disease, $\mathrm{RD}$, disease, health, adverse effect, mortality, death, morbidity, hospital admission; and (3) China, Chinese, Taiwan, Hong Kong, river delta. The bibliographies of the articles identified using the search criteria above were also screened to expand our review. Furthermore, it is important to note that "respiratory disease (RD)" in present study referred to "all diseases of the respiratory system according to ICD-9 460-519 or ICD-10 J00-J98", not including its single or sub-classification. EndNote Software (VersionX7, Thomson Corporation, Stamford, CT, USA) was employed to manage the citations.

\subsection{Literature Selection and Data Extraction}

All of the studies included in our review were selected using the following inclusion criteria: (1) Chinese and English epidemiological studies with health outcomes related to RD mortality and RD hospital admission due to short-term exposure to ambient $\mathrm{NO}_{2}$ in China; (2) studies focusing on 
short-term exposures, defined as the duration of up to 7 days to ambient $\mathrm{NO}_{2}$ associated with $\mathrm{RD}$ mortality and RD hospital admission; (3) articles included quantitative exposure-response associations (relative risk (RR), odds ratios (OR), excess risk (ER: also called attributable risk (AR), defined as the difference between the proportion of subjects in a population with a particular disease who were exposed to a specified risk factor and the proportion of subjects with that same disease who were not exposed) [30], and their 95\% confidence intervals (95\% CI)), and individual health risk estimates were expressed according to unit change in $\mathrm{NO}_{2}$ mass concentration; (4) study population was healthy people of all age and all gender; (5) exposure to ambient $\mathrm{NO}_{2}$ in the natural environment; (6) the analysis used the "International Classification of Diseases ICD-9 460-519 or ICD-10 J00-J98"; (7) time-series and case-crossover studies were used; (8) single-pollutant model results were available; and (9) for duplicated or derived articles conducted in same location, study period, data source, pollutants, or health outcomes, only the most recent publication was included. In addition, single-city study with different time periods from multi-cities study was also accepted [31]. The study followed the PRISMA guidelines for conducting systematic reviews and meta-analyses [32].

We excluded: (1) studies conducted in other countries; (2) studies presenting association between other air pollutants and other health outcomes; (3) reviews or duplicate publications; (4) conference abstracts without sufficient information, government reports, and other non-peer reviewed articles; (5) study duration less than one year; (6) studies with inconvertible data; (7) research without a city-specific quantitative short-term exposure-response relationship or only with stratified results; (8) studies with subjects designed to specific high risk groups (e.g., infants, children, the elderly, pregnant women, patients and smokers); (9) indoor, occupational or accidental exposures; (10) research on non-respiratory diseases, single or sub-classification of respiratory diseases.

For consistency, we generally ignored the distinctions between the measures of relative risk (RR) and odds ratio (OR) in present study, because the OR mathematically approximates the RR when the absolute risk of RD mortality and RD hospital admission due to $\mathrm{NO}_{2}$ exposure in population is low; we therefore extracted both of them in synthesis for simplicity [33]. Additionally, we followed Atkinson's [34] protocols for selecting lags To be precise, if only one lag estimate was presented, it would be recorded for analyses; if multiple lags were presented, the lag would be selected based on the criteria: (1) the lag that the author focused on or stated as a priori; (2) the lag that was of the most statistically significance (positive or negative) and (3) the lag with the largest effect estimate (positive or negative). All individual effect estimates should be expressed as standardized increment in RD mortality and RD hospital admission due to per $10 \mu \mathrm{g} / \mathrm{m}^{3}$ change in $\mathrm{NO}_{2}$ concentration using the following formula:

$$
\begin{gathered}
\mathrm{RR}_{(\text {standardized })}=\mathrm{RR}_{(\text {original })}^{\text {Incemen }(10) / \text { Increment }(\text { original })} \\
1 \mathrm{ppb}=1.88 \mu \mathrm{g} / \mathrm{m}^{3}\left(\text { 1atmosphere and a temperature of } 25^{\circ} \mathrm{C}\right) \\
\operatorname{ER}(\%)=(\mathrm{RR}-1) \times 100 \%
\end{gathered}
$$

Two reviewers (Jiyao Sun and Dongyang He) independently screened the titles and abstracts. Then, full texts were reviewed to decide eligibility for inclusion. Disagreement was resolved by discussion. If the argument still existed, another reviewer (Meng Wang) was consulted to determine the final decisions. Data extraction was also conducted by two independent reviewers (Dongyang He and Meng Wang) for comparisons. Disagreements were resolved by consulting the third reviewer (Jiyao Sun).

In total, 29 studies were included in this meta-analysis. The title, authors, study period, publication year, study design, city, annual mean concentration of $\mathrm{NO}_{2}$, health risk estimates (RR or OR and $95 \%$ confidence interval), number of events and adjusted confounding factors were extracted and entered into Microsoft Excel database (Version 2010, Microsoft, Redmond, WA, USA). Stata Software (Version 12.0, StataCorp., College Station, TX, USA) was used to conduct meta-analysis. 


\subsection{Quality Assessment}

Because no validated and standardized scales were recommended to assess the quality of time-series and case-crossover studies, we evaluated the quality of total 29 individual studies based on a scale from a related meta-analysis [35], which is composed of three items: respiratory disease (RD) diagnosis, air pollutant measurement and adjustment of confounders (Supplemental Table S1).

\subsubsection{RD Diagnosis}

We determined the diagnosis of RD if coded according to International Classification of Diseases ICD-9 460-519 or ICD-10 J00-J98.

\subsubsection{Air Pollutant Measurement}

We considered the study at low risk of bias if the frequency of air pollutant measurement was performed daily, otherwise high risk of bias would be recognized.

\subsubsection{Adjustment of Confounders}

In terms of the potential confounders, long-term trends, seasonality, meteorological parameters (temperature and relative humidity), day of week (DOW), public holidays, influenza epidemics were recorded to assess the quality of the studies. Studies adjusting at least four items were considered at low risk of bias.

\subsection{Meta-Analysis}

In this meta-analysis, generic inverse variance method was used to summarize effects estimates from the individual studies identified [36]. We first examined the heterogeneity among all 29 studies using the standard $\mathrm{I}^{2}$ test. We observed heterogeneity at $\mathrm{I}^{2}$ exceeding $50 \%$. We therefore used a random-effects model to pool effect estimates if $\mathrm{I}^{2}>50 \%$ or otherwise used a fixed-effects model. We estimated heterogeneity through meta-regression and subgroup analysis. Then, funnel plots with Egger's test were created to assess publication bias at an $\alpha$ level of 0.1 [37]. The trim-and-fill method [38] was used to adjust asymmetry if publication bias was observed. Finally, sensitivity analyses were performed to evaluate the robustness of the correlation results.

\subsection{Sensitivity Analysis}

To evaluate the robustness of the correlation results, we conducted a leave-one-out sensitivity analysis where the pooled meta-estimate was re-estimated excluding one study iteratively at a time to test the robustness of the main study findings to the exclusion of any single study [21]. If the pooled estimates remained stable after the sensitivity analysis, suggesting main results were not being driven by any single study.

\section{Results}

A total of 29 studies, including 14 Chinese studies and 15 English studies, from the Mainland China, Taiwan and Hong Kong were selected by searching in PubMed, Web of Science, CNKI and Wanfang databases and using the search criteria above (Supplemental Figure S1). These studies spanned research across 18 cities and included 25 time-series studies and four case-crossover studies. RD mortality and RD hospital admission were reported by 21 studies and eight studies, respectively (Table 1). All included studies were at low risk of bias according to the results of quality assessment. The annual mean concentrations of $\mathrm{NO}_{2}$ ranged from 23 to $83 \mu \mathrm{g} / \mathrm{m}^{3}$, and most of the reported concentrations exceeded the World Health Organization (WHO) air quality guidelines [39]. All RRs or ORs ( $95 \%$ confidence intervals) in the following contexts were based on a $10 \mu \mathrm{g} / \mathrm{m}^{3}$ increase in $\mathrm{NO}_{2}$ concentration. 
Table 1. RRs ${ }^{1}$ or ORs ${ }^{2}$ of $\mathrm{RD}^{3}$ mortality and RD hospital admission due to short-term exposure to $\mathrm{NO}_{2}{ }^{4}$ and detailed information for each city by study.

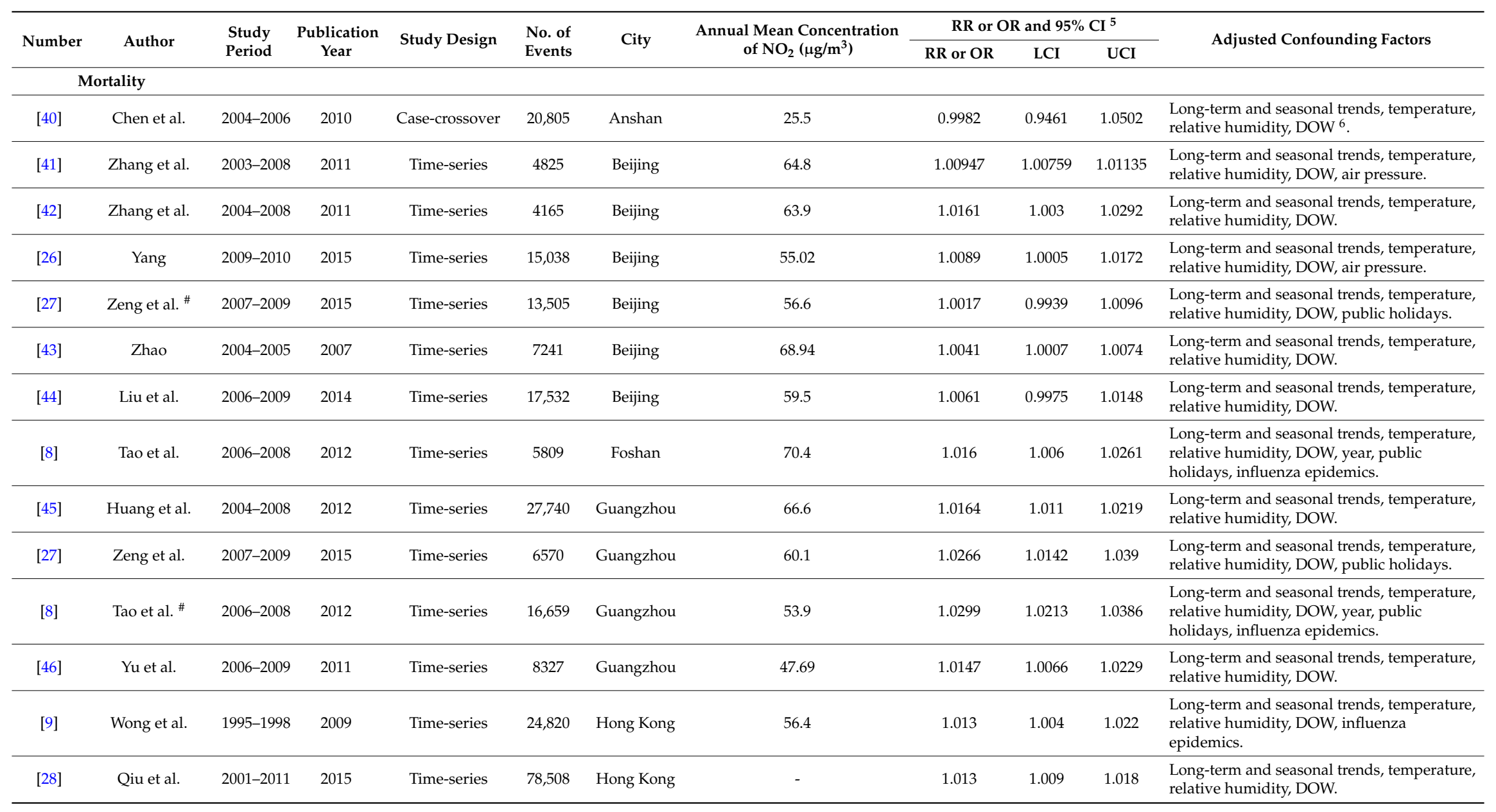


Table 1. Cont.

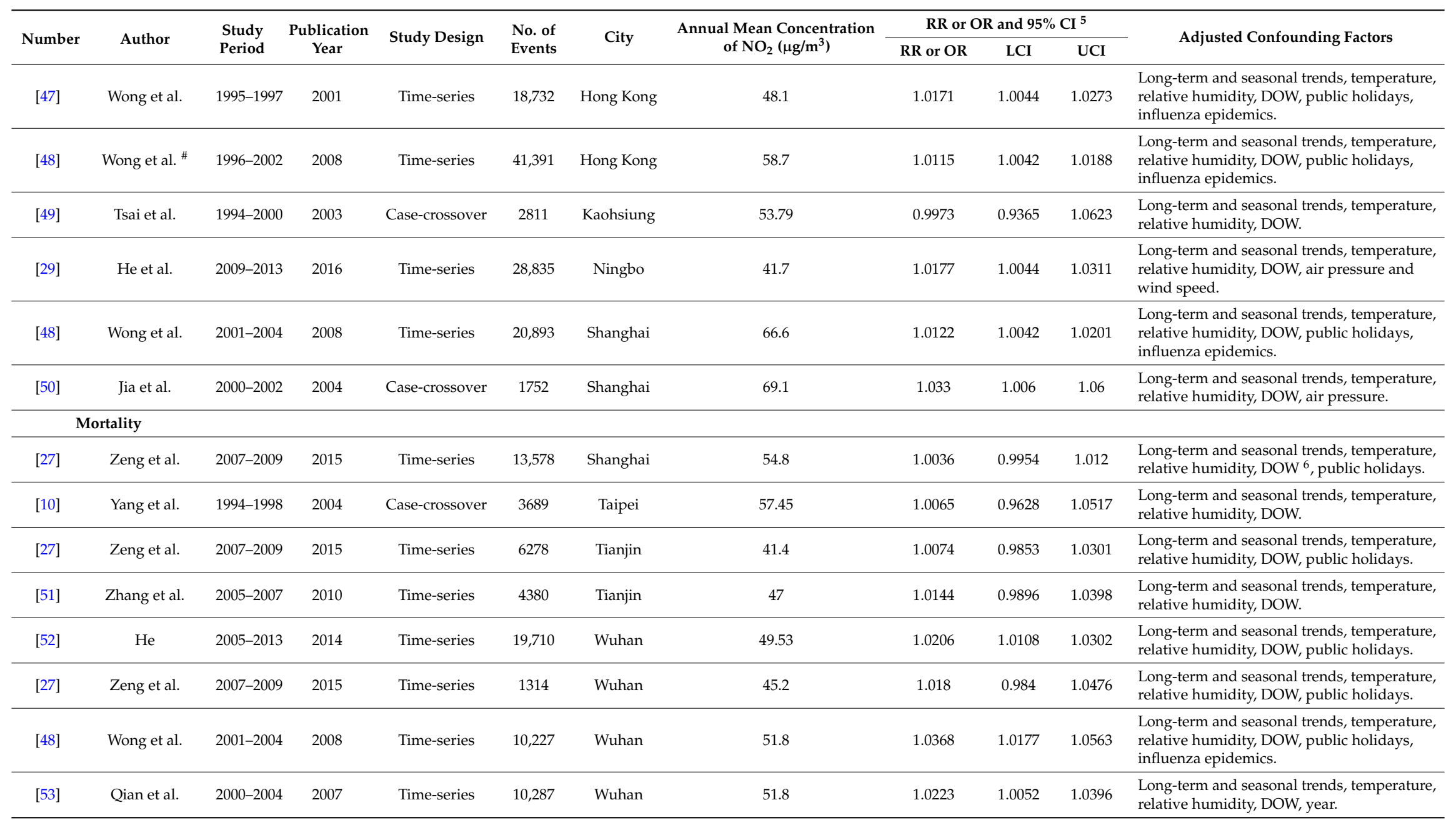


Table 1. Cont.

\begin{tabular}{|c|c|c|c|c|c|c|c|c|c|c|c|}
\hline \multirow{2}{*}{ Number } & \multirow{2}{*}{ Author } & \multirow{2}{*}{$\begin{array}{l}\text { Study } \\
\text { Period }\end{array}$} & \multirow{2}{*}{$\begin{array}{l}\text { Publication } \\
\text { Year }\end{array}$} & \multirow{2}{*}{ Study Design } & \multirow{2}{*}{$\begin{array}{l}\text { No. of } \\
\text { Events }\end{array}$} & \multirow{2}{*}{ City } & \multirow{2}{*}{$\begin{array}{c}\text { Annual Mean Concentration } \\
\text { of } \mathrm{NO}_{2}\left(\mu \mathrm{g} / \mathrm{m}^{3}\right)\end{array}$} & \multicolumn{3}{|c|}{ RR or OR and $95 \% \mathrm{CI}^{5}$} & \multirow{2}{*}{ Adjusted Confounding Factors } \\
\hline & & & & & & & & RR or OR & LCI & UCI & \\
\hline [27] & Zeng et al. & 2007-2009 & 2015 & Time-series & 1898 & Xi'an & 54 & 1.0161 & 0.9746 & 1.0594 & $\begin{array}{l}\text { Long-term and seasonal trends, temperature } \\
\text { relative humidity, DOW, public holidays. }\end{array}$ \\
\hline$[8]$ & Tao et al. & $2006-2008$ & 2012 & Time-series & 4056 & Zhongshan & 48.4 & 1.0344 & 1.0167 & 1.0525 & $\begin{array}{l}\text { Long-term and seasonal trends, temperature } \\
\text { relative humidity, DOW, year, public } \\
\text { holidays, influenza epidemics. }\end{array}$ \\
\hline [8] & Tao et al. & $2006-2008$ & 2012 & Time-series & 1205 & Zhuhai & 38.1 & 1.0246 & 0.9841 & 1.0667 & $\begin{array}{l}\text { Long-term and seasonal trends, temperature } \\
\text { relative humidity, DOW, year, public } \\
\text { holidays, influenza epidemics. }\end{array}$ \\
\hline [12] & Zhang et al. & $2008-2011$ & 2014 & Time-series & 46,752 & Guangzhou & 56 & 1.0147 & 1.0062 & 1.0233 & $\begin{array}{l}\text { Long-term and seasonal trends, temperature } \\
\text { relative humidity, DOW, air pressure. }\end{array}$ \\
\hline$[14]$ & Liu & 2010-2012 & 2014 & Time-series & 24,792 & Hangzhou & 83 & 1.007 & 1.0025 & 1.0144 & $\begin{array}{l}\text { Long-term and seasonal trends, temperature } \\
\text { relative humidity, DOW, public holidays. }\end{array}$ \\
\hline [11] & Wong et al & 1994-1995 & 1999 & Time-series & 61,320 & Hong Kong & 51.39 & 1.02 & 1.013 & 1.028 & $\begin{array}{l}\text { Long-term and seasonal trends, temperature } \\
\text { relative humidity, DOW, year, public } \\
\text { holidays. }\end{array}$ \\
\hline$[54]$ & Lan & $2006-2008$ & 2012 & Time-series & 5808 & Jinchang & 23 & 1.0336 & 1.0009 & 1.068 & $\begin{array}{l}\text { Long-term and seasonal trends, temperature } \\
\text { relative humidity, DOW. }\end{array}$ \\
\hline [55] & Chen et al. & 2005-2007 & 2010 & Time-series & 144,540 & Shanghai & 57 & 1.0001 & 0.993 & 1.0073 & $\begin{array}{l}\text { Long-term and seasonal trends, temperature } \\
\text { relative humidity, DOW, public holidays. }\end{array}$ \\
\hline [56] & Bao et al. & 2005-2009 & 2013 & Time-series & 24,935 & Urumqi & 48.8 & 1.0056 & 1.0024 & 1.0121 & $\begin{array}{l}\text { Long-term and seasonal trends, temperature } \\
\text { relative humidity, DOW. }\end{array}$ \\
\hline [25] & Wang et al. & 2013-2015 & 2016 & Time-series & 3314 & Wuhan & 63.13 & 1.005 & 0.984 & 1.026 & $\begin{array}{l}\text { Long-term and seasonal trends, temperature } \\
\text { relative humidity, DOW, public holidays, air } \\
\text { pressure. }\end{array}$ \\
\hline
\end{tabular}


The overall analyses have explained significant associations between ambient $\mathrm{NO}_{2}$ and $\mathrm{RD}$ in Chinese population in present meta-analysis, based on 29 studies [RD mortality: combined estimate (95\% CI): 1.014 (1.011, 1.017); $\mathrm{I}^{2}=65 \%$; Egger's test: $p<0.05$; RD hospital admission: combined estimate (95\% CI): 1.010 (1.005, 1.015); I ${ }^{2}=66.2 \%$; Egger's test: $\left.p>0.1\right]$.

\subsection{Mortality}

The effect estimates of RD mortality for each city by study are shown in Table 1. For each $10 \mu \mathrm{g} / \mathrm{m}^{3}$ increase in $\mathrm{NO}_{2}$ concentration, the risk of $\mathrm{RD}$ mortality increased by $1.4 \%$ (95\% CI: $1.1 \%$, $1.7 \%$ ) (Figure 1). Significant heterogeneity was observed $\left(\mathrm{I}^{2}=65 \%\right)$.

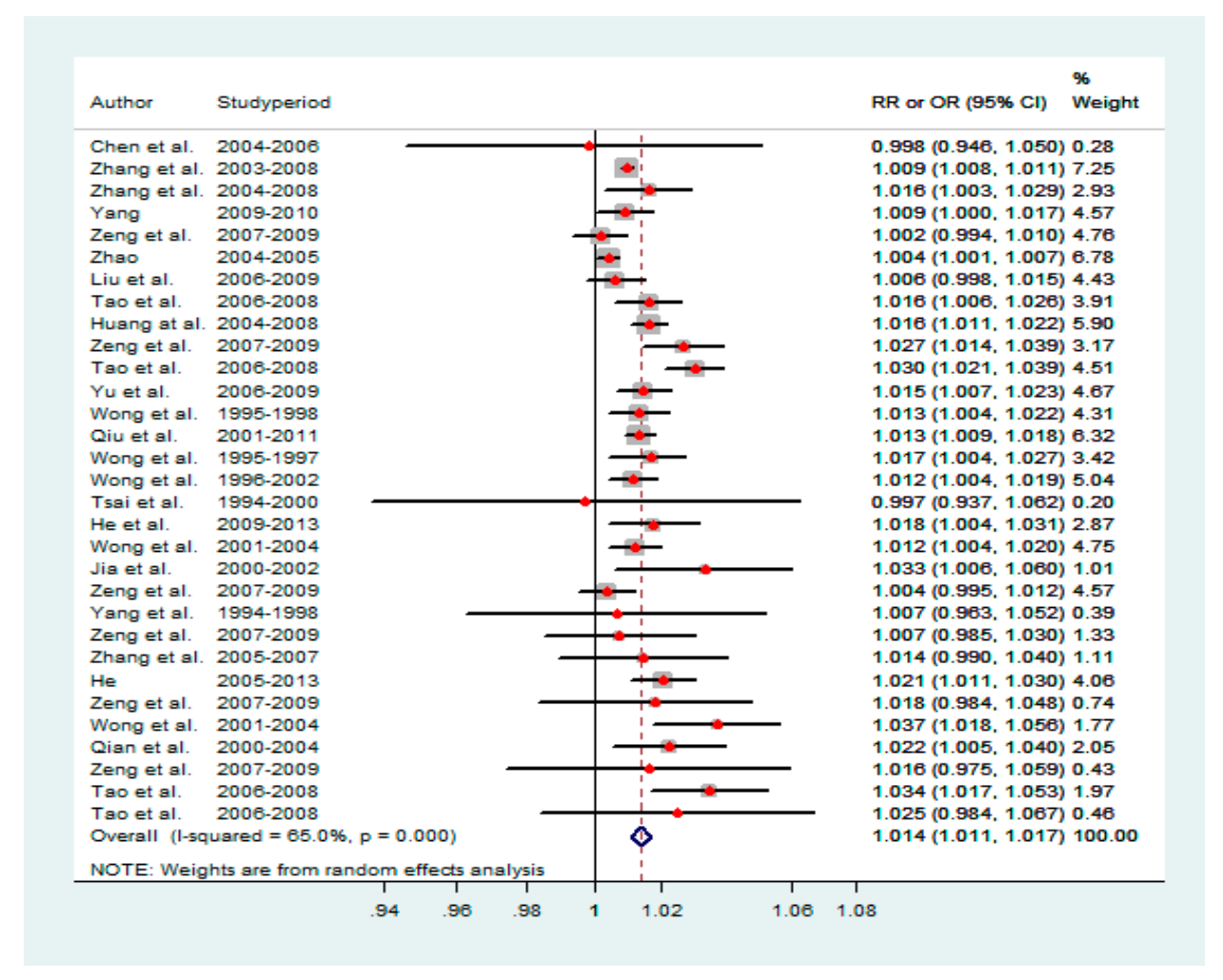

Figure 1. The effect of ambient $\mathrm{NO}_{2}$ pollution on $\mathrm{RD}$ mortality.

\subsubsection{Meta-Regression}

For all of the selected studies, we conducted meta-regression by study geographical region, study design and annual mean concentration of $\mathrm{NO}_{2}$. Results showed that geographical region stratification (south and north) had a significant impact on the association between $\mathrm{NO}_{2}$ and $\mathrm{RD}$ mortality $(p<0.01)$. The effects of annual mean concentration of $\mathrm{NO}_{2}$ and study design (time-series and case-crossover) were not significant $(p>0.05)$ (Table 2).

Table 2. Results of meta-regression.

\begin{tabular}{ccccccc}
\hline \multirow{2}{*}{ Category } & Regression Coefficient & \multirow{2}{*}{ SE } & T & P & \multicolumn{2}{c}{ 95\% CI } \\
\cline { 5 - 7 } & & & & & LCI & LCI \\
\hline Region & 1.009707 & 0.0026565 & 3.67 & 0.001 & 1.004289 & 1.015155 \\
Concentration & 0.999765 & 0.0001986 & -1.18 & 0.247 & 0.9993583 & 1.000172 \\
Study design & 1.00385 & 0.010779 & 0.36 & 0.723 & 0.9820451 & 1.02614 \\
\hline
\end{tabular}




\subsubsection{Subgroup Analysis}

The main meta-regression models were stratified by geographic region in China. Results showed that heterogeneity significantly decreased after stratifying the model by region. For southern Chinese cities, each $10 \mu \mathrm{g} / \mathrm{m}^{3}$ increase in $\mathrm{NO}_{2}$ concentration was associated with an increased risk of $\mathrm{RD}$ mortality of $1.7 \%$ (95\% CI: $1.4 \%, 2.1 \%$ ), which was higher than the overall risk of $1.4 \%$. For northern cities, each additional $10 \mu \mathrm{g} / \mathrm{m}^{3}$ increase in $\mathrm{NO}_{2}$ concentration was associated with an increased risk of RD mortality of $0.7 \%$ (95\% CI: $0.5 \%, 1.0 \%)$, which was lower than the overall risk. Importantly, the increased risk of $\mathrm{RD}$ mortality associated with $\mathrm{NO}_{2}$ concentration in the southern area was higher than that in the north (Figure 2).

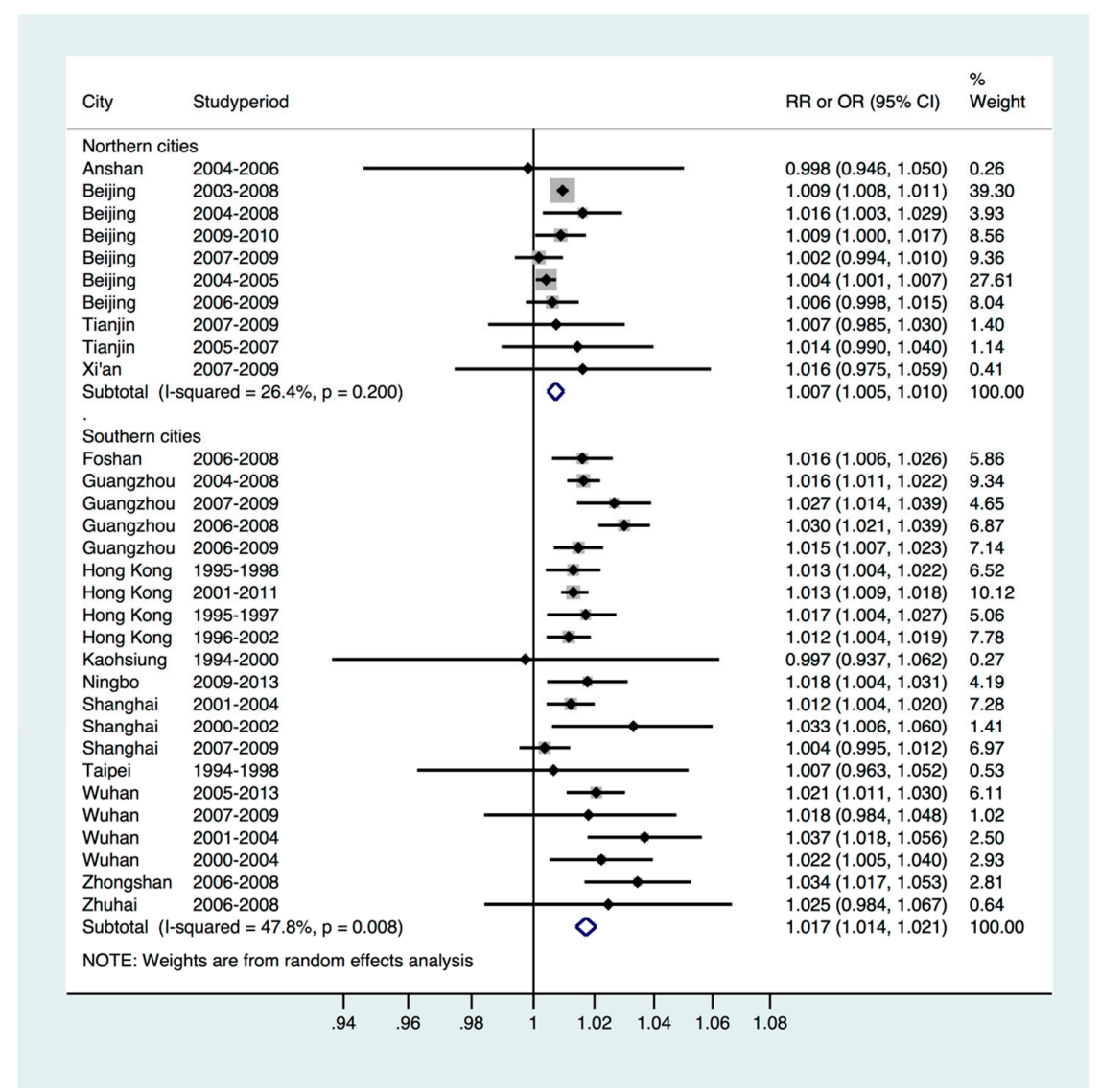

Figure 2. Regional analysis of the contribution of $\mathrm{NO}_{2}$ to $\mathrm{RD}$ mortality.

\subsubsection{Publication Bias and Sensitivity Analysis}

Egger's test showed a significant effect for publication bias $(p<0.05)$. Trim-and-fill method was used to adjust asymmetry, which did not alter the direction of the effect but reduced the effect size (adjusted overall combined estimates: 1.013; 95\% CI: 1.010, 1.016).

The pooled estimate of RD mortality remained stable after the sensitivity analysis, suggesting main results were not being driven by any single study.

\subsection{Hospital Admission}

Hospital admissions were reported by 8 time-series studies in Jinchang, Lanzhou, Urumqi, Hong Kong, Guangzhou, Shanghai, Wuhan, Hangzhou. The estimates for each city by study are shown in Table 1. For each $10 \mu \mathrm{g} / \mathrm{m}^{3}$ increase in $\mathrm{NO}_{2}$ concentration, the risk of $\mathrm{RD}$ hospital admission increased by $1.0 \%$ (95\% CI: $0.5 \%, 1.5 \%$ ) (Figure 3 ). 


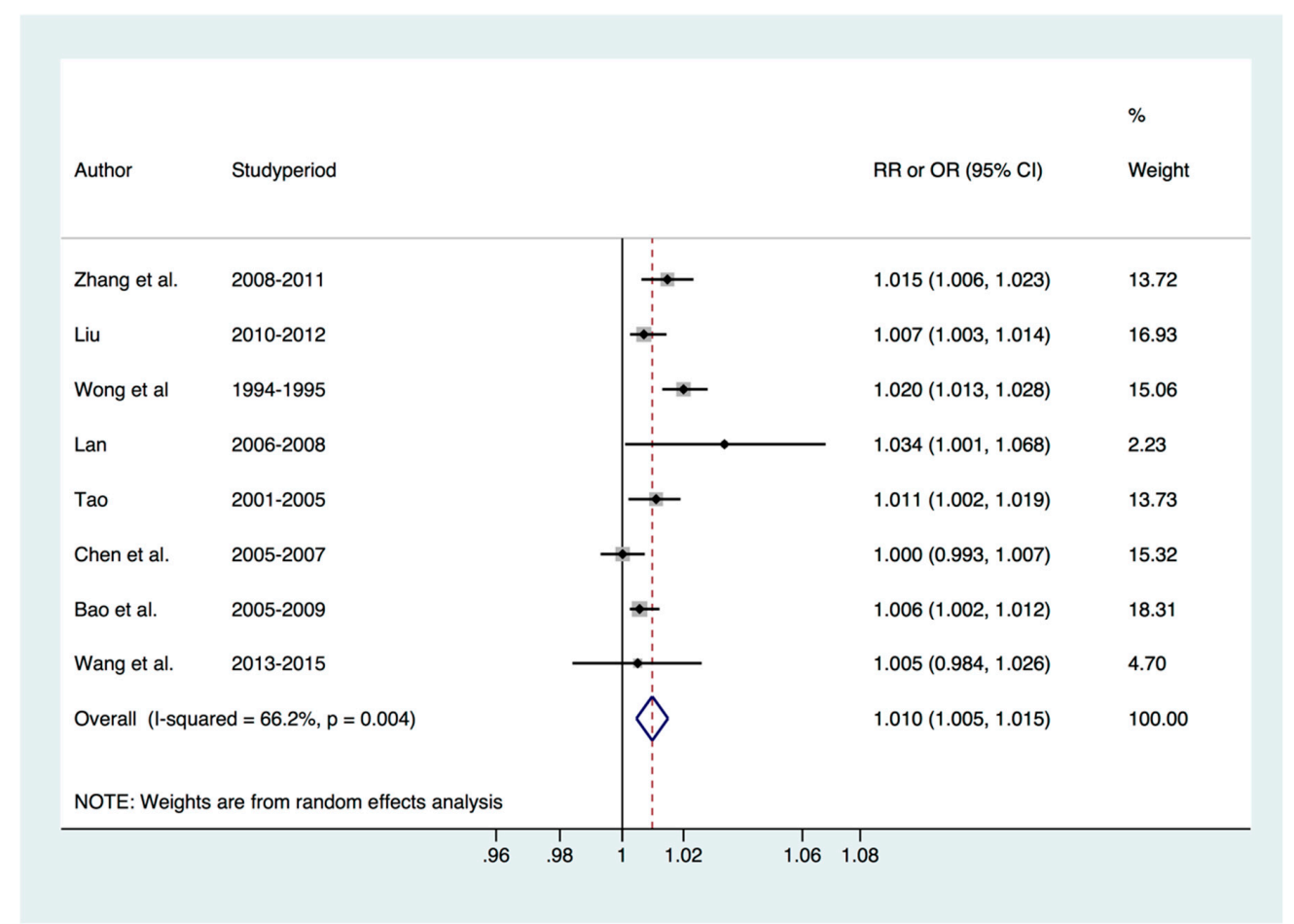

Figure 3. The effect of ambient $\mathrm{NO}_{2}$ pollution on $\mathrm{RD}$ hospital admission.

\subsubsection{Heterogeneity and Sensitivity Analysis}

Heterogeneity was detected across studies of $\mathrm{RD}$ hospital admission $\left(\mathrm{I}^{2}=66.2 \%\right)$. Subgroup analysis by region and annual mean concentration of $\mathrm{NO}_{2}$ did not reduce the size of the heterogeneity estimate (Table 3). Furtherly, we found heterogeneity was significantly reduced by dropping Wong's [12] study through sensitivity analysis. However, the combined effect size was reduced to 1.008 (95\% CI: $1.003,1.012)$ and was still positive (Table 4$)$.

Table 3. Subgroup analysis for the contribution of $\mathrm{NO}_{2}$ to $\mathrm{RD}$ hospital admission.

\begin{tabular}{cccccc}
\hline \multirow{2}{*}{ Stratification } & \multirow{2}{*}{$\begin{array}{c}\text { Study Characteristics } \\
\text { (Number of Studies) }\end{array}$} & Combined Estimate & \multicolumn{2}{c}{$\mathbf{9 5 \% \text { CI }}$} & \multirow{2}{*}{$\mathbf{I}^{\mathbf{2}}$} \\
\cline { 4 - 6 } Research region & Northern cities (3) & 1.01 & 1.00 & 1.02 & $44.80 \%$ \\
& Southern cities (5) & 1.01 & 1.00 & 1.02 & $75.70 \%$ \\
\hline \multirow{2}{*}{ Annual mean concentration of $\mathrm{NO}_{2}$} & $23 \mu \mathrm{g} / \mathrm{m}^{3}-53 \mu \mathrm{g} / \mathrm{m}^{3}(4)$ & 1.01 & 1.00 & 1.02 & $75.00 \%$ \\
& $53 \mu \mathrm{g} / \mathrm{m}^{3}-83 \mu \mathrm{g} / \mathrm{m}^{3}(4)$ & 1.01 & 1.00 & 1.01 & $55.00 \%$ \\
\hline
\end{tabular}

Table 4. Results of sensitivity analysis for the contribution of $\mathrm{NO}_{2}$ to $\mathrm{RD}$ hospital admission.

\begin{tabular}{ccccc}
\hline \multirow{2}{*}{ Study Omitted } & \multirow{2}{*}{ Combined Estimates } & \multicolumn{2}{c}{$\mathbf{9 5 \%}$ CI } & \multirow{2}{*}{$\mathbf{I}^{\mathbf{2}}$} \\
\cline { 3 - 4 } & & LCI & UCI & \\
\hline Lan & 1.009 & 1.004 & 1.015 & $65.7 \%$ \\
Tao & 1.010 & 1.003 & 1.016 & $70.5 \%$ \\
Bao et al. & 1.011 & 1.004 & 1.017 & $66.2 \%$ \\
Wong et al. & 1.008 & 1.003 & 1.012 & $42.2 \%$ \\
Zhang et al. & 1.009 & 1.003 & 1.015 & $67.6 \%$ \\
Chen et al. & 1.011 & 1.006 & 1.016 & $58.4 \%$ \\
Wang et al. & 1.010 & 1.004 & 1.016 & $70.8 \%$ \\
Lui & 1.010 & 1.004 & 1.017 & $70.5 \%$ \\
Combined estimates & 1.010 & 1.005 & 1.015 & $66.2 \%$ \\
\hline
\end{tabular}




\subsubsection{Publication Bias}

Egger's test showed no significant publication bias effect was detected $(p>0.1)$.

\section{Discussion}

This study conducted a systematic review and meta-analyses of the evidence regarding the association between short-term exposure to $\mathrm{NO}_{2}$ and $\mathrm{RD}$ in China. In this quantitative analysis, the evidence suggests each $10 \mu \mathrm{g} / \mathrm{m}^{3}$ increase in $\mathrm{NO}_{2}$ concentration corresponded to $1.4 \%(95 \% \mathrm{CI}$ : $1.1 \%, 1.7 \%$ ) increase in RD mortality and 1.0\% (95\% CI: 0.5\%, 1.5\%) increase in RD hospital admission in the Chinese population. After stratifying by geographic region in China, we found the risk of RD mortality associated with $\mathrm{NO}_{2}$ concentration was higher in the southern area $(1.7 \%)$ than in the north $(0.7 \%)$.

The results found in this study can be compared with other studies conducted in other parts of the world. As for RD mortality, Lai's meta-analysis [23] reported that in the Chinese population, a $10 \mu \mathrm{g} / \mathrm{m}^{3}$ increase in $\mathrm{NO}_{2}$ concentration was associated with a $2.2 \%$ increase in RD mortality. Their result was higher than that found in our study. The Public Health and Air Pollution in Asia (PAPA) [48] study showed the combined excess RD mortality risks was $1.63 \%$ per additional $10 \mu \mathrm{g} / \mathrm{m}^{3}$ of $\mathrm{NO}_{2}$ in three Chinese cities (Hong Kong, Shanghai, Wuhan). Chen [3] reported a combined estimate of $2.52 \%$ increase in $\mathrm{RD}$ mortality per $10 \mu \mathrm{g} / \mathrm{m}^{3}$ increase in $\mathrm{NO}_{2}$ in 17 Chinese cities. Shang's [22] systematic review in China reported that an increase of $10 \mu \mathrm{g} / \mathrm{m}^{3}$ of $\mathrm{NO}_{2}$ was associated with a $1.62 \%$ increase in RD mortality. Atkinson [34] reported that a $10 \mu \mathrm{g} / \mathrm{m}^{3}$ increase of $\mathrm{NO}_{2}$ concentration corresponded to a $1.74 \%$ increases in RD mortality in a meta-analysis of time-series models from the Asian literature. Liu's [24] meta-analysis reported a $10 \mu \mathrm{g} / \mathrm{m}^{3}$ increase in $\mathrm{NO}_{2}$ concentration corresponded to $1.39 \%$ increase in RD mortality in China. It was fair to suppose that the discrepancy was partially due to the changes among Chinese cities in levels of exposure, chemical compositions of ambient air pollution, city background characteristics such as urbanization level, medical and hygiene standards, age structure and underlying susceptibility of the population during the rapid economic development in recent years [23].

The European Approach (APHEA)-2 project included 30 European cities [5] and found that a $10 \mu \mathrm{g} / \mathrm{m}^{3}$ increase in $\mathrm{NO}_{2}$ concentrations was associated with a $0.38 \%$ increase in RD mortality, much lower than the association found in the current study. The EpiAir study [57] conducted in 10 Italian cities found statistically significant evidence that a $10 \mu \mathrm{g} / \mathrm{m}^{3}$ increase of $\mathrm{NO}_{2}$ was associated with a $3.48 \%$ increase in RD mortality, which was much higher than our result. It should be noted that Kinney and Özkaynak [58] found no significant association between respiratory deaths and $\mathrm{NO}_{2}$ concentration in Los Angeles County, USA. In terms of hospital admissions, only one meta-analysis study [23] reported a positive relationship between $\mathrm{NO}_{2}$ concentration and RD-associated hospital admission in Chinese population. Specifically, an increase of $10 \mu \mathrm{g} / \mathrm{m}^{3}$ of $\mathrm{NO}_{2}$ was associated with a $0.6 \%$ increase in RD hospital admission in the Chinese population. Chen's [55] epidemiological research in Shanghai found that $\mathrm{RD}$ hospital admission was not significantly associated with $\mathrm{NO}_{2}$. However, Fusco's [59] study in Italy found an increase in the interquartile range of $\mathrm{NO}_{2}$ concentration corresponded to $2.5 \%$ increase in RD hospital admissions. A quantitative summary of APHEA study results in five west European cities [60] revealed an almost 2\% increase in RD hospital admission for an increase of $50 \mu \mathrm{g} / \mathrm{m}^{3}$ of $\mathrm{NO}_{2}$.

In our analysis of $\mathrm{RD}$ mortality, we found the risk associated with increased $\mathrm{NO}_{2}$ concentration in the southern areas of China was higher than that in the northern areas. Several reasons may explain these geographic differences. First, the differences in the age distribution of the populations residing in the northern and southern regions of China. Among the 10 provinces with the largest number of older adults in China, six are in the south [61]. Qian [62] reported that significant deterioration of respiratory function, respiratory infection, and even respiratory failure are more likely to occur in the elderly. Therefore, a higher percentage increase of RD mortality might happen in the southern area due to the preponderance of older adults residing there compared to the northern area. A second reason for these 
geographical differences may be due to variation in the sensitivity of the population to $\mathrm{NO}_{2}$ levels. For southern cities, the mean reported $\mathrm{NO}_{2}$ concentration is $51.9 \mu \mathrm{g} / \mathrm{m}^{3}$ whereas it is $53.7 \mu \mathrm{g} / \mathrm{m}^{3}$ for northern cities. Local residents in northern cities are living in a more serious $\mathrm{NO}_{2}$ polluted areas, and their respiratory system be more resistant to $\mathrm{NO}_{2}$ pollution [56]. This might cause lower excess risk of RD mortality in the north than in the south. In terms of hospital admissions, no significant difference was observed after stratification by geographic region. Additionally, we found that the heterogeneity observed was caused by one study (Wong) [11]. By comparing our results with other studies, we believed that study period, geographical features, climate patterns, pollutant composition and population sensitivity might lead to this heterogeneity [63].

What needs to be considered is that although the above results have indicated adverse effects of $\mathrm{NO}_{2}$ on $\mathrm{RD}$ mortality and $\mathrm{RD}$ hospital admission, but the role of $\mathrm{NO}_{2}$ as a surrogate of unmeasured pollutants cannot be ruled out [57]. Sarnat's $[64,65]$ research reported that high correlation between $\mathrm{NO}_{2}$ and $\mathrm{PM}_{2.5}$ have been found which suggest the possibility that the $\mathrm{NO}_{2}$ effects could be due in part to confounding from particulate matter through assessing epidemiological studies on adverse health effects of $\mathrm{PM}_{2.5}$, so $\mathrm{NO}_{2}$ may be considered mainly as a surrogate of ultrafine PM. Seaton and Dennekamp [66] consistently indicated that $\mathrm{NO}_{2}$ may serve as a marker for other pollutants, such as fine particles formed in high-temperature combustion of fossil fuels. Even though the existing multi-pollutant analyses are not competent for completely assessing the independent adverse health effects of $\mathrm{NO}_{2}$ which has the possibility as a surrogate of particulate matter, the present study did provide positive evidence that short-term exposure to $\mathrm{NO}_{2}$ was associated with an increased risk of RD mortality and RD hospital admission. Therefore, further research should be carried out to identify the independent effects of different pollutants, such as $\mathrm{NO}_{2}$ and their interaction [51].

\section{Strengths}

The current study has several notable strengths. First, we systematically collected and pooled additional epidemiological evidence that has been previously synthesized by expanding the publication year to 2016 in order to provide more current estimates of the magnitude of adverse health effects of ambient $\mathrm{NO}_{2}$ pollution in Chinese population. Second, we stratified the RD mortality estimates by geographical locations to provide contrasting result between southern area and northern area of China, and are the first find that risk of $\mathrm{RD}$ mortality associated with increasing $\mathrm{NO}_{2}$ concentration was higher in the southern area than in the northern area.

\section{Limitations}

Several potential limitations of the present analysis should be taken into account. First, publication bias was noted in analyses examining the relationship between $\mathrm{NO}_{2}$ and $\mathrm{RD}$ mortality. This may be due to the authors being more likely to emphasize and publish positive results than negative ones [22]. Second, heterogeneity existed in analyses of both RD outcomes perhaps because the individual study effects came from different study periods and from 18 different Chinese cities. The lag selection used might also have introduced heterogeneity into our meta-analysis [67]. Third, both time-series studies and case-crossover studies were selected in this meta-analysis. The results of case-crossover studies may be stronger than those of time-series studies, because case-crossover design can effectively control the confounding factors, such as smoking, diet, heredity, living conditions of the population and season factors by matching the case period and control period [68]. Thus, the inclusion of these two different study designs may have influenced the combined estimates and caused the heterogeneity we observed. Fourth, the combined estimates in present analysis may not accurately represent the actual exposure to $\mathrm{NO}_{2}$ to some extent because the exposure measurements used in each study were based on a small number of fixed outdoor monitors, a common limitation in ecological studies [69]. Furthermore, the age- and gender-specific data which were important effect modifiers for identifying subgroups susceptible to $\mathrm{NO}_{2}$ pollution exposure were also didn't extracted in present study. Additionally, although all included studies have controlled the major 
confounders including long-term and seasonal trends, temperature and relative humidity, day of week, some other confounding factors, such as public hospitals and influenza epidemics, which have not been adjusted among all individual studies, may increase the risk of bias to a certain extent. Finally, only single-pollutant model results were included. We did not consider the potential synergistic effects of $\mathrm{NO}_{2}$ in multiple pollutants models [70].

\section{Conclusions}

The present meta-analysis provides updated scientific evidence that short-term exposure to ambient $\mathrm{NO}_{2}$ is associated increased risk of $\mathrm{RD}$ mortality and $\mathrm{RD}$ hospital admission in the Chinese population. Furthermore, extend the literature by being the first to find that the risk of RD mortality associated with increasing $\mathrm{NO}_{2}$ concentration in the southern area of China is higher than that in the northern area. Additional evidence is needed to guide Chinese policy makers to improve air quality and minimize the health impact of air pollutants.

Supplementary Materials: The following are available online at www.mdpi.com/1660-4601/14/6/646/s1, Figure S1: Flow chart for study retrieval and selection process, Table S1: Quality assessment of included studies in the systematic review.

Acknowledgments: This article is based on research funded by the Independent Innovation Foundation of Shandong University (2014JC021), National Natural Science Foundation of China (71273156). The authors would like to express gratitude to Yue Zhang and Chuyun Wang for providing necessary materials and helpful comments on the article.

Author Contributions: Jian Wang conceived and designed the research, and provided supervision and guidance to the writing of the article. Jiyao Sun, Dongyang He and Meng Wang selected articles and extracted data. Jiyao Sun conducted data analysis and drafted the first version of the manuscript. Jian Wang and Andrew J. Barnes reviewed, edited and modified the manuscript critically for important intellectual content.

Conflicts of Interest: The authors declare no conflict of interest.

\section{References}

1. Liu, L.; Yang, X.; Liu, H.; Wang, M.; Welles, S.; Márquez, S.; Frank, A.; Haas, C.N. Spatial-Temporal analysis of air pollution, climate change, and total mortality in 120 cities of China, 2012-2013. Front. Public Health 2016, 4, 123. [CrossRef] [PubMed]

2. Samet, J.; Krewski, D. Health effects associated with exposure to ambient air pollution. J. Toxicol. Environ. Health Part A 2007, 70, 227-242. [CrossRef] [PubMed]

3. Chen, R.; Samoli, E.; Wong, C.M.; Huang, W.; Wang, Z.; Chen, B.; Kan, H. Associations between short-term exposure to nitrogen dioxide and mortality in 17 Chinese cities: The China Air Pollution and Health Effects Study (CAPES). Environ. Int. 2012, 45, 32-38. [CrossRef] [PubMed]

4. Kan, H.; London, S.J.; Chen, G.; Zhang, Y.; Song, G.; Zhao, N.; Jiang, L.; Chen, B. Season, sex, age, and education as modifiers of the effects of outdoor air pollution on daily mortality in Shanghai, China: The Public Health and Air Pollution in Asia (PAPA) Study. Environ. Health Perspect. 2008, 116, 1183-1188. [CrossRef] [PubMed]

5. Samoli, E.; Aga, E.; Touloumi, G.; Nisiotis, K.; Forsberg, B.; Lefranc, A.; Pekkanen, J.; Wojtyniak, B.; Schindler, C.; Niciu, E.; et al. Short-term effects of nitrogen dioxide on mortality: An analysis within the APHEA project. Eur. Respir. J. 2006, 27, 1129-1138. [CrossRef] [PubMed]

6. Rajarathnam, U.; Sehgal, M.; Nairy, S.; Patnayak, R.C.; Chhabra, S.K.; Kilnani; Ragavan, K.V. Part 2. Time-series study on air pollution and mortality in Delhi. Res. Rep. 2011, 157, 47-74.

7. Blomberg, A.; Krishna, M.T.; Bocchino, V.; Biscione, G.L.; Shute, J.K.; Kelly, F.J.; Frew, A.J.; Holgate, S.T.; Sandström, T. The inflammatory effects of $2 \mathrm{ppm} \mathrm{NO}$ on the airways of healthy subjects. Am. J. Respir. Crit. Care Med. 1997, 156, 418-424. [CrossRef] [PubMed]

8. Tao, Y.; Huang, W.; Huang, X.; Zhong, L.; Lu, S.E.; Li, Y.; Dai, L.; Zhang, Y.; Zhu, T. Estimated acute effects of ambient ozone and nitrogen dioxide on mortality in the pearl river delta of Southern China. Environ. Health Perspect. 2012, 120, 393-398. [CrossRef] [PubMed] 
9. Wong, T.W.; Tam, W.S.; Yu, T.S.; Wong, A.H.S. Associations between daily mortalities from respiratory and cardiovascular diseases and air pollution in Hong Kong, China. Occup. Environ. Med. 2002, 59, 30-35. [CrossRef] [PubMed]

10. Yang, C.Y.; Chang, C.C.; Chuang, H.Y.; Tsai, S.S.; Wu, T.N.; Ho, C.K. Relationship between air pollution and daily mortality in a subtropical city: Taipei, Taiwan. Environ. Int. 2004, 30, 519-523. [CrossRef] [PubMed]

11. Wong, T.W.; Tai, S.L.; Yu, T.S.; Neller, A.; Wong, S.L.; Tam, W.; Pang, S.W. Air pollution and hospital admissions for respiratory and cardiovascular diseases in Hong Kong. Occup. Environ. Med. 1999, 56, 679-683. [CrossRef] [PubMed]

12. Zhang, Z.; Wang, J.; Chen, L.; Chen, X.; Sun, G.; Zhong, N.; Kan, H.; Lu, W. Impact of haze and air pollution-related hazards on hospital admissions in Guangzhou, China. Environ. Sci. Pollut. Res. Int. 2014, 21, 4236-4244. [CrossRef] [PubMed]

13. Tao, Y. Physical and Chemical Characteristics of Atmospheric Particulate Matter and Their Impact on Human Health in Lanzhou; Lanzhou University: Lanzhou, China, 2009.

14. Liu, J.Y. Time-Series Analysis of Air Pollution and Health Effect of the Residents in Hangzhou; Hangzhou Dianzi University: Hangzhou, China, 2014.

15. Sheehan, M.C.; Lam, J.; Navas-Acien, A.; Chang, H.H. Ambient air pollution epidemiology systematic review and meta-analysis: A review of reporting and methods practice. Environ. Int. 2016, 92, 647-656. [CrossRef] [PubMed]

16. Stieb, D.M.; Judek, S.; Burnett, R.T. Meta-analysis of time-series studies of air pollution and mortality: Effects of gases and particles and the influence of cause of death, age, and season. J. Air Waste Manag. Assoc. 2002, 52, 470-484. [CrossRef] [PubMed]

17. Stieb, D.M.; Judek, S.; Burnett, R.T. Meta-analysis of time-series studies of air pollution and mortality: Update in relation to the use of generalized additive models. J. Air Waste Manag. Assoc. 2003, 53, 258-261. [CrossRef] [PubMed]

18. Shin, H.H.; Stieb, D.M.; Jessiman, B.; Goldberg, M.S.; Brion, O.; Brook, J.; Ramsay, T.; Burnett, R.T. A temporal, multicity model to estimate the effects of short-term exposure to ambient air pollution on health. Environ. Health Perspect. 2008, 116, 1147-1153. [CrossRef] [PubMed]

19. Touloumi, G.; Katsouyanni, K.; Zmirou, D.; Schwartz, J.; Spix, C.; de Leon, A.P.; Tobias, A.; Quennel, P.; Rabczenko, D.; Bacharova, L. Short-term effects of ambient oxidant exposure on mortality: A combined analysis within the APHEA project. Am. J. Epidemiol. 1997, 146, 177-185. [CrossRef] [PubMed]

20. Zmirou, D.; Schwartz, J.; Saez, M.; Zanobetti, A.; Wojtyniak, B.; Touloumi, G.; Spix, C.; León, A.P.D.; Moullec, Y.L.; Bacharova, L. Time-series analysis of air pollution and cause-specific mortality. Epidemiology 1998, 9, 495-503. [CrossRef] [PubMed]

21. Lu, F.; Xu, D.; Cheng, Y.; Dong, S.; Guo, C.; Jiang, X.; Zheng, X. Systematic review and meta-analysis of the adverse health effects of ambient $\mathrm{PM}_{2.5}$ and $\mathrm{PM}_{10}$ pollution in the Chinese population. Environ. Res. 2015, 136, 196-204. [CrossRef] [PubMed]

22. Shang, Y.; Sun, Z.; Cao, J.; Wang, X.; Zhong, L.; Bi, X.; Li, H.; Liu, W.; Zhu, T.; Huang, W. Systematic review of Chinese studies of short-term exposure to air pollution and daily mortality. Environ. Int. 2013, 54, 100-111. [CrossRef] [PubMed]

23. Lai, H.K.; Tsang, H.; Wong, C.M. Meta-analysis of adverse health effects due to air pollution in Chinese populations. BMC Public Health 2013, 13, 360. [CrossRef] [PubMed]

24. Liu, C.Y.; Huang, F.; Yang, Z.Z.; Sun, Z.R.; Huang, C.B.; Liu, H.M.; Shao, D.B.; Zhang, W.; Ren, Y.; Tang, W.J.; et al. A Meta analysis on the associations between air pollution and respiratory mortality in China. Chin. J. Epidemiol. 2015, 36, 889-895.

25. Wang, X.Y.; Jiao, S.L.; Wang, W.C.; Zeng, X.; Hu, C.P.; Wang, L. The effect of air pollution on hospital admission in Wuhan in 2013-2015. In Proceedings of the Annual Meeting in 2016 of the Chinese Society of Environmental Sciences, Haikou, China, 13-14 October 2016; p. 6.

26. Yang, Y. Study on Air Pollution and Population Health in Beijing; Peking Union Medical College: Beijing, China, 2015.

27. Zeng, Q.; Li, G.; Zhang, L.; Tian, L.; Pan, X. Acute effects of $\mathrm{SO}_{2}$ and $\mathrm{NO}_{2}$ on mortality in the six cities of China. Chin. J. Prev. Med. 2015, 49, 1085-1091. 
28. Qiu, H.; Tian, L.; Ho, K.F.; Pun, V.C.; Wang, X.; Yu, I.T. Air pollution and mortality: Effect modification by personal characteristics and specific cause of death in a case-only study. Environ. Pollut. 2015, 199, $192-197$. [CrossRef] [PubMed]

29. He, T.; Yang, Z.; Liu, T.; Shen, Y.; Fu, X.; Qian, X.; Zhang, Y.; Wang, Y.; Xu, Z.; Zhu, S. Ambient air pollution and years of life lost in Ningbo, China. Sci. Rep. 2016, 6, 22485. [CrossRef] [PubMed]

30. Benichou, J. Attributable Risk; John Wiley \& Sons, Ltd.: New York, NY, USA, 2006; p. 226.

31. Zheng, X.Y.; Ding, H.; Jiang, L.N.; Chen, S.W.; Zheng, J.P.; Qiu, M.; Zhou, Y.X.; Chen, Q.; Guan, W.J. Association between air pollutants and asthma emergency room visits and hospital admissions in time series studies: A systematic review and meta-analysis. PLoS ONE 2015, 10, e0138146. [CrossRef] [PubMed]

32. Moher, D.; Liberati, A.; Tetzlaff, J.; Altman, D.G.; Group, T.P. Preferred reporting items for systematic reviews and meta-analyses: The PRISMA statement. J. Chin. Integr. Med. 2014, 18, 889-896.

33. Greenland, S. Quantitative methods in the review of epidemiologic literature. Epidemiol. Rev. 1987, 9, 1-30. [CrossRef] [PubMed]

34. Atkinson, R.W.; Cohen, A.; Mehta, S.; Anderson, H.R. Systematic review and meta-analysis of epidemiological time-series studies on outdoor air pollution and health in Asia. Air Qual. Atmos. Health 2012, 5, 383-391. [CrossRef]

35. Song, X.; Liu, Y.; Hu, Y.; Zhao, X.; Tian, J.; Ding, G.; Wang, S. Short-term exposure to air pollution and cardiac arrhythmia: A meta-analysis and systematic review. Int. J. Environ. Res. Public Health 2016, 13, 642. [CrossRef] [PubMed]

36. Song, Q.; Christiani, D.C.; Wang, X.R.; Ren, J. The global contribution of outdoor air pollution to the incidence, prevalence, mortality and hospital admission for chronic obstructive pulmonary disease: A systematic review and meta-analysis. Int. J. Environ. Res. Public Health 2014, 11, 11822-11832. [CrossRef] [PubMed]

37. Egger, M.; Davey, S.G.; Schneider, M.; Minder, C. Bias in meta-analysis detected by a simple, graphical test. BMJ 1997, 315, 629-634. [CrossRef] [PubMed]

38. Duval, S.; Tweedie, R. Trim and fill: A simple funnel-plot-based method of testing and adjusting for publication bias in meta-analysis. Biometrics 2000, 56, 455-463. [CrossRef] [PubMed]

39. World Health Organization. WHO Air Quality Guidelines for Particulate Matter, Ozone, Nitrogen Dioxide and Sulfur Dioxide; Summary of Risk Assessment; World Health Organization: Geneva, Switzerland, 2005.

40. Chen, R.J. Ambient air pollution and daily mortality in Anshan, China: A time-stratified case-crossover analysis. Sci. Total Environ. 2010, 408, 6086-6091. [CrossRef] [PubMed]

41. Zhang, F.; Li, L.; Krafft, T.; Lv, J.; Wang, W.; Pei, D. Study on the association between ambient air pollution and daily cardiovascular and respiratory mortality in an urban district of Beijing. Int. J. Environ. Res. Public Health 2011, 8, 2109-2123. [CrossRef] [PubMed]

42. Zhang, J.Y.; Meng, H.Y.; Zhang, G.B. Relationship between air pollution and daily respiratory system disease mortality in Chaoyang District, Beijing: A time-series analysis. J. Environ. Health 2011, 21, 223-236.

43. Zhao, Y. Study on Health Effect and Economic Loss on Urban Citizens Caused by Air Pollution; China University of Geosciences: Beijing, China, 2007.

44. Liu, N.M.; Liu, L.Q.; Mei-Mei, X.U.; Liang, F.C.; Pan, X.C. Relationships between ambient nitrogen dioxide and population mortality of respiratory disease in Beijing. J. Environ. Health 2014, 31, 565-568.

45. Huang, X.L.; Dai, L.Z.; Lu, P.; Shang, Y.; Li, Y.; Tao, Y.B.; Huang, W. Time-series analysis on the acute mortality affected by air pollution, in the city of Guangzhou, 2004-2008. Zhonghua Liu Xing Bing Xue Za Zhi 2012, 33, 210. [PubMed]

46. Yu, I.T.S.; Zhang, Y.H.; Tam, W.W.S.; Yan, Q.H.; Xu, Y.J.; Xun, X.J.; Wu, W.; Ma, W.J.; Tian, L.W.; Tse, L.A. Effect of ambient air pollution on daily mortality rates in Guangzhou, China. Atmos. Environ. 2012, 46, 528-535. [CrossRef]

47. Wong, C.M.; Ma, S.; Hedley, A.J.; Lam, T.H. Effect of air pollution on daily mortality in Hong Kong. Environ. Health Perspect. 2001, 109, 335-340. [CrossRef] [PubMed]

48. Wong, C.M.; Vichit-Vadakan, N.; Kan, H.; Qian, Z. Public Health and Air Pollution in Asia (PAPA): A multicity study of short-term effects of air pollution on mortality. Environ. Health Perspect. 2007, 116, 1195-1202. [CrossRef] [PubMed]

49. Tsai, S.S.; Huang, C.H.; Goggins, W.B.; Wu, T.N.; Yang, C.Y. Relationship between air pollution and daily mortality in a tropical city: Kaohsiung, Taiwan. J. Toxicol. Environ. Health Part A 2003, 66, 1341-1349. [CrossRef] [PubMed] 
50. Jia, J.; Kan, H.D.; Chen, B.H.; Xu, W.; Xia, D.X. Association of air pollution with daily mortality in Zhabei District of Shanghai: A case, crossover analysis. J. Environ. Health 2004, 21, 279-282.

51. Zhang, Y.S.; Zhou, M.G.; Jia, Y.P.; Hu, Y.S.; Zhang, J.L.; Jiang, G.H.; Pan, X.C. Time-series analysis on the association between gaseous air pollutants and daily mortality in urban residents in Tianjin. Epidemiology 2010, 31, 1158-1162. [CrossRef]

52. He, X.S. Epidemiological Study on the Assocaition of Air Pollution and Its Constituents with the Cardiopulmonary Mortality and the Risk of Coronary Heart Disease; Huazhong University of Science and Technology: Wuhan, China, 2014.

53. Qian, Z.; He, Q.; Lin, H.M. Short-term effects of gaseous pollutants on cause-specific mortality in Wuhan, China. J. Air Waste Manag. Assoc. 2007, 57, 785-793. [PubMed]

54. Lan, L. Effects of Air Pollution on Public Health in Jinchang; Lanzhou University: Lanzhou, China, 2013.

55. Chen, R.; Chu, C.; Tan, J.; Cao, J.; Song, W.; Xu, X.; Jiang, C.; Ma, W.; Yang, C.; Chen, B. Ambient air pollution and hospital admission in Shanghai, China. J. Hazard. Mater. 2010, 181, 234-240. [CrossRef] [PubMed]

56. Bao, Y.X.; Yibulayin, X.; Wu, W.-H.; Liu, X.L. Time-series analysis on relationship between air pollution and daily hospital for respiratory system diseases in Urumqi. J. Xinjiang Med. Univ. 2013, 36, 537-541.

57. Chiusolo, M.; Cadum, E.; Stafoggia, M.; Galassi, C.; Berti, G.; Faustini, A.; Bisanti, L.; Vigotti, M.A.; Dessì, M.P.; Cernigliaro, A. Short-term effects of nitrogen dioxide on mortality and susceptibility factors in 10 Italian Cities: The EpiAir study. Environ. Health Perspect. 2011, 119, 1233-1238. [CrossRef] [PubMed]

58. Kinney, P.L.; Özkaynak, H. Associations of daily mortality and air pollution in Los Angeles County. Environ. Res. 1991, 54, 99-120. [CrossRef]

59. Fusco, D.; Forastiere, F.; Michelozzi, P.; Spadea, T.; Ostro, B.; Arcà, M.; Perucci, C.A. Air pollution and hospital admissions for respiratory conditions in Rome, Italy. Eur. Respir. J. 2001, 17, 1143-1150. [CrossRef] [PubMed]

60. Spix, C.; Anderson, H.R.; Schwartz, J.; Vigotti, M.A.; Letertre, A.; Vonk, J.M.; Touloumi, G.; Balducci, F.; Piekarski, T.; Bacharova, L. Short-term effects of air pollution on hospital admissions of respiratory diseases in Europe: A quantitative summary of APHEA study results. Arch. Environ. Health 1998, 53, 54-64. [CrossRef] [PubMed]

61. Wang, Z.Y.; Sun, R.; Han, Z.L.; Liu, F.C. Research on the measure of chinese population aging level and spatial correlation. Areal Res. Dev. 2013, 3, 138-143.

62. Qian, G.S. Clinical characteristics of respiratory diseases in the elderly. Chin. J. Health Care Med. 2011, 13, 177-179.

63. Chen, R.J. The Health Effects of Complex Air Pollution in 17 Chinese Cities; Fudan University: Shanghai, China, 2013.

64. Sarnat, J.A.; Schwartz, J.; Catalano, P.J.; Suh, H.H. Gaseous pollutants in particulate matter epidemiology: Confounders or surrogates? Environ. Health Perspect. 2001, 109, 1053-1061. [CrossRef] [PubMed]

65. Sarnat, J.A.; Brown, K.W.; Schwartz, J.; Coull, B.A.; Koutrakis, P. Ambient gas concentrations and personal particulate matter exposures: Implications for studying the health effects of particles. Epidemiology 2005, 16, 385-395. [CrossRef] [PubMed]

66. Seaton, A.; Dennekamp, M. Hypothesis: Ill health associated with low concentrations of nitrogen dioxide-An effect of ultrafine particles? Thorax 2003, 58, 1012-1015. [CrossRef] [PubMed]

67. Anderson, H.R.; Atkinson, R.W.; Peacock, J.L.; Sweeting, M.J.; Marston, L. Ambient particulate matter and health effects: Publication bias in Studies of short-term associations. Epidemiology 2005, 16, 155-163. [CrossRef] [PubMed]

68. Zhang, Z.; Zhan, S.Y. Case-crossover design. Chin. J. Epidemiol. 2001, 22, 304-306.

69. Zhang, S.; Li, G.; Tian, L.; Guo, Q.; Pan, X. Short-term exposure to air pollution and morbidity of COPD and asthma in East Asian area: A systematic review and meta-analysis. Environ. Res. 2016, 148, 15-23. [CrossRef] [PubMed]

70. Dominici, F.; Peng, R.D.; Barr, C.D.; Bell, M.L. Protecting human health from air pollution: Shifting from a single-pollutant to a multipollutant approach. Epidemiology 2010, 21, 187-194. [CrossRef] [PubMed] 